Área Abierta. Revista de comunicación

audiovisual y publicitaria

ISSN: 2530-7592

http://dx.doi.org/10.5209/ARAB.52964

\title{
De la palabra del héroe a la feminidad o del pensamiento al deseo. Una relectura de los "Cuentos morales" de Éric Rohmer
}

\author{
Arnau Vilaró i Moncasí ${ }^{1}$
}

Recibido: 15 de junio de 2016 / Aceptado: 22 de noviembre de 2016

Resumen. Del héroe de "Cuentos morales" (1963-1972) a la heroína de "Comedias y proverbios" (19811987) Éric Rohmer establece el paso de un cine fundado en una lógica de acción a un cine de videncia. De acuerdo con esta idea, a partir de la cual Gilles Deleuze piensa el paso de la imagen-movimiento a la imagen-tiempo, las siguientes páginas retoman el estudio de la primera serie del cineasta para ver en la feminidad abandonada por el héroe (Haydée, Maud, Chloé o Claire) los principios con los que Rohmer concibe sus heroínas posteriores y una nueva lógica de relato. Para ello, por un lado, el artículo revisita los estudios que abordan la puesta en escena de "Cuentos morales" a partir del pensamiento del héroe y de la palabra en particular; por otro lado, propone el deseo y la idea de alteridad como el método que permite pensar la imagen y la palabra en su conjunto, esto es, la mostración y el lenguaje, elementos con los que, siguiendo las ideas de André Bazin, Rohmer define la naturaleza ambigua del cinematógrafo. Palabras clave: Éric Rohmer; "Cuentos morales"; héroe; palabra; deseo; feminidad; visibilidad

\section{[en] From the Word of the Hero to Femininity, or from Thought to Desire. A Re-Reading of Éric Rohmer's "Moral Tales"}

\begin{abstract}
From the hero of "Six Moral Tales" (1963-1972) to the heroine of "Comedies and Proverbs" (1981-1987) Éric Rohmer establishes the passage of a cinema based on a logic of action to a cinema of clairvoyance. According to this idea, from which Gilles Deleuze thinks the passage of the movementimage to the time-image, the following paper take up the study of the first series of the filmmaker to watch femininity abandoned by the hero (Haydée, Maud, Chloé or Claire) the principles that define subsequent heroines of Rohmer and his new narrative logic. To do this, on the one hand, the article revisits studies addressing the mise en scène of "Moral Tales" from the thought of the hero and his word; on the other hand, it proposes the desire and the idea of otherness as the method that suggests the image and the word as a whole, that is to say, showing and language, elements that, following the ideas of André Bazin, Rohmer defines the ambiguous nature of cinematograph.
\end{abstract}

Keywords: Éric Rohmer; "Moral Tales"; Hero; Word; Desire; Femininity; Visibility

Sumario. 1. De la acción del héroe a preocupación por lo visible. 2. El lenguaje y las cosas. O la densidad de la palabra. 3. La mano sobre la rodilla de Claire. 4. "Una era el error, la otra la verdad". Ambigüedad femenina en "Cuentos morales". 5. A modo de conclusión. 6. Bibliografía

1 Universidad Nacional Autónoma de México

E-mail: arnau.vilaro@gmail.com 
Cómo citar: Vilaró i Moncasí, A. (2017) De la palabra del héroe a la feminidad o del pensamiento al deseo. Una relectura de los "Cuentos morales" de Éric Rohmer, en Área Abierta. Revista de comunicación audiovisual y publicitaria 17 (2), 183-197. http://dx.doi.org/10.5209/ARAB.52964

\section{De la acción del héroe a preocupación por lo visible}

"Antes me rompía la cabeza para elegir. Y ahora he visto que no hay nada que elegir. Que no estaba obligada a decidir por algo que realmente no quería". La frase de Félicie (Charlotte Véry) en Conte d'hiver (Éric Rohmer, 1992) sintetiza el paso en la obra de Rohmer de la serie de "Cuentos morales" (1963-1972) a "Comedias y proverbios" (1981-1987). Si en la primera serie de films el cineasta transforma el pensamiento de su héroe en una decisión moral, en la segunda serie la heroína no obra desde la elección, sino desde la indecisión, entregándose por completo a la inquietud por ver y confiando toda su búsqueda a la creencia de un afuera superior a su pensamiento. En el mismo film, Félicie dirá a su amante: "No te dije 'he comprendido', te dije 'he visto'. No hay nada que discutir. [...] No lo puedes comprender. Soy yo quien ha visto y no tú".

De una serie a la otra, Rohmer plantea un giro en el relato cinematográfico que coincide con el cambio de paradigma que según Gilles Deleuze hallamos entre el clasicismo y la modernidad: de un cine fundado en la acción a un cine que privilegia la situación del personaje y que se preocupa, por tanto, por lo que el personaje ve. De acuerdo con las tesis del filósofo francés, el héroe de "Cuentos morales" respondería al circuito sensoriomotor propio de la imagen-movimiento y la lógica del film se definiría a partir de la acción del héroe; por su lado, en "Comedias y proverbios", el paso de una imagen a la otra respondería a la mirada de las heroínas frente a una situación que supera toda acción posible: a la palabra que controla y decide el devenir de la acción se le impone el vagabundeo que metaforiza la crisis sensoriomotor ${ }^{2}$. En otras palabras, mientras que en "Cuentos morales", cuando la duda aparece, el héroe decide huir, abandonar la aventura del conocimiento del otro, el período vacacional, volver a su vida normal y recuperar su estabilidad; en "Comedias y proverbios", en cambio, la acción, en términos de Deleuze, no se "repara", no hay "actualización del estado de las cosas", sino que la acción se desarrolla en la suspensión generada por la inquietud por ver, sin crear otro mundo que la suspensión misma. En este sentido, la segunda serie de films de Rohmer transformaría la contradicción que habita entre el pensamiento y la palabra del narrador/héroe de "Cuentos morales" en la única posibilidad de acción. Ellas mostrarían un nuevo gesto, ya no de posesión como el que encarna la mano de Jérôme sobre la rodilla de Claire (Le genou de Claire, 1970), sino un gesto fundado en el movimiento de búsqueda, y en el que la decisión, si decisión alguna existe, debería aparecer fuera de la conciencia del personaje: en la llegada de un rayo verde tras la puesta del sol (Le rayon vert, 1986), en el cruce de miradas en un tren después del fracaso del amor (Le beau mariage, 1982) o en una impresión invisible a nuestros ojos, como la que determina la decisión de Julieta al final de Die Marquise von $O \ldots$... (1976).

2 Véase Deleuze (2003-2004). Sobre la diferencia entre ambos sistemas de imágenes, ver Rancière (2005: 129-146). 
A partir de una relectura de "Cuentos morales", el siguiente artículo cuestiona la separación entre las dos primeras series de films del cineasta francés. Nuestro objetivo es ver cómo en la primera serie hallamos los indicios del abandono a la inquietud por lo visible a través del cual Rohmer concibe las heroínas de "Comedias y proverbios". Antes de que la palabra del héroe se convierta en decisión (acción), antes de que la heroína sea sustituida por otra de acuerdo con la misma decisión del héroe (Jacqueline por Sylvie, Maud por Françoise, Chloé por Michèle o Haydée por Carole), la duda que crea Rohmer en la mirada hacia el sujeto femenino de "Cuentos morales" aparece como la misma inquietud sobre lo visible a la que se someterían las heroínas de "Comedias y proverbios". La mirada a Haydée junto a la orilla ( $\mathrm{Ca}$ colectionneuse, 1967), el acercamiento a la cama de Maud (Ma nuit chez Maud, 1969), el acto de secar el cuerpo de Chloé (L'amour l'après-midi, 1972) o la mano que acaricia la rodilla de Claire (Le genou de Claire). Bajo la tentación del héroe de materializar su deseo, antes de tomar la decisión de escapar, las imágenes de aproximación a la mujer y la duda del héroe que la misma aproximación provoca testimonian una suspensión, un abandono de la acción, una crisis del esquema sensoriomotor. Las imágenes muestran la exploración de una mirada que no acepta la palabra, que excluye la participación del pensamiento. Nuestra hipótesis es que la presencia del sujeto femenino en "Cuentos morales" supone un desplazamiento del interés por la acción a la preocupación por lo visible, siendo este desplazamiento decisivo, por un lado, para considerar la primera serie de Rohmer dentro de la lógica de la imagen-tiempo deleuziana y, por otro lado, para comprender el diálogo con el que el cineasta define la naturaleza de la imagen cinematográfica entre la ontología y el lenguaje.

Las páginas que siguen sostienen que el mismo desplazamiento entre la acción y la visión coincide con el paso del pensamiento al deseo, o lo que es lo mismo, del relato como conciencia del héroe al relato como apertura a la feminidad. Para abordarlo, revisitaremos, por un lado, el vínculo de la palabra y la imagen, potencias a partir de las cuales los estudios hasta la fecha plantean la puesta en escena de "Cuentos morales" como expresión del pensamiento del héroe. Por otro lado, cuestionaremos la feminidad y en concreto el rostro abandonado en "Cuentos morales" (Haydée, Maud, Claire, Chloé), como un elemento de ruptura y de especificidad en la posterior obra de Rohmer.

\section{EI lenguaje y las cosas. O la densidad de la palabra}

"La imagen no está hecha para significar, sino para mostrar [...], para significar existe una herramienta excelente, el lenguaje hablado"3, escribe Rohmer en 1965. Todavía bajo la pluma de su nombre real, Maurice Scherer, el futuro cineasta ya exclamaba a favor de Flaherty y Murnau: "¡Viva el cine que sólo pretende mostrar y nos dispensa del fraude de decir!"4. Tomando el cine como el arte de mostrar, Rohmer encuentra la respuesta a las preguntas de André Bazin', y de este modo lo

3 Éric Rohmer a Biette, Bontemps y Comolli (1965: 32-43).

4 Scherer, M. "Vanidad de la pintura", Cahiers du Cinéma, núm. 3 (1951). Extraído de Rohmer (2000a: 77).

5 Véase Bazin (2008). 
expresa también a Jean Narboni: "Para mí, en el cine lo importante era la ontología y no el lenguaje, por retomar los términos de Bazin. Ontológicamente, el cine dice algo que las demás artes no dicen"6. Y sin embargo, como señala Tom Gunning en la última gran obra dedicada al cineasta, Rohmer et les Autres (2010), la herencia recibida de Bazin radica precisamente en "respetar el peso y la resistencia a la vez del lenguaje y de las cosas"?.

En sus años de crítico, Rohmer argumentó que el film no podía renunciar a la tradición de las otras artes y que su condición de arte moderno pasaba justamente por convocar esta tradición ${ }^{8}$. Como cineasta, Rohmer evidencia esta necesidad en la inspiración que toma del romanticismo pictórico de Greuze, Füssili o Friedrich para pensar la imagen del universo de Kleist en Die Marquise von O..., y sobre todo en el respeto por la obra original y la cuestión moral de su adaptación en la pantalla, desde Perceval le gallois (1977) hasta L'anglaise et le duc (2001) o Triple agent (2003)9. En la misma voluntad de diálogo entre el lenguaje existente y la especificidad fílmica, Rohmer escribió dos textos en defensa de la palabra y de su estatuto dentro del film: "Pour un cinéma parlant", publicado durante la etapa del cineasta en Cahiers du cinéma, y "Le film et les trois plans du discours: indirect, direct, hyper direct", publicado tras el estreno de Die Marquise von $O$... En este segundo artículo, citando los Discursos de Corneille, Rohmer recupera las dos ideas principales de la Poética de Aristóteles, lo necesario y lo verosímil: "Es necesario todo lo que es indispensable para la claridad de la intriga. Es verosímil lo que los protagonistas podrían decir entre ellos, en una situación, sin preocuparse de informar al público"10. Según el futuro cineasta, en el cine lo necesario y lo verosímil se verían afectados por un desplazamiento del diálogo. Por un lado, en las películas anteriores a los años sesenta, los diálogos parecen sobrecargados de necesario debido a la presencia del monólogo, del comentario o del signo gráfico; por otro lado, los films que desean escapar de las "reglas" del teatro lo hacen mediante la supresión de diálogo, pero entonces lo verdadero proclama la muerte de lo verosímil. ¿Cómo conceder de nuevo al diálogo la carga de la verosimilitud que tenía en la poética aristotélica entre el relato y su representación? ¿Cómo concebir el diálogo, a su vez, como un elemento de necesidad para el espectador? En "Pour un cinéma parlant", Rohmer vindica el estatuto que la palabra merece en tanto que materia del cine sonoro. Su texto concluye en tono de manifiesto: "Hace demasiado tiempo que esperamos que [el cine] nos dé una prueba que la época del sonoro ha empezado". El crítico recuerda la secuencia de Le crime de Monsieur Lange (Jean Renoir, 1935) donde René Lefèvre

6 Éric Rohmer a Jean Narboni. "El tiempo de la crítica. Entrevista con Eric Rohmer”, Cahiers du Cinéma, (noviembre de 1983). Extraído de Rohmer (2000a: 23).

7 Gunning, “Éric Rohmer et l'héritage du réalisme cinématographique”, en Herpe (2007: 20).

8 Nos referimos sobre todo a la célebre serie de artículos que, bajo el título de "Le celluloïd et le marbre", Rohmer publicó en cinco números de la revista Cahiers du Cinéma durante 1955.

9 En la entrevista de Noël Herpe al cineasta a propósito de la reedición de Le cellulö̈ et le marbre, Rohmer declara: "Cuando adapto obras antiguas tengo la misión de conservar el patrimonio. No tengo derecho a modificarlas - derecho que tomaban sin embargo los grandes autores clásicos en el siglo XVII (Corneille y Racine escribiendo una Berenice o una Andrómaca, Molière escribiendo El avaro...). Tengo una cierta moral, un respeto del patrimonio" (Rohmer, 2010: 100).

10 Rohmer. "Le film et les trois plans du discours: indirect, direct, hyper direct", Cahiers Renaud-Barrault, núm. 96 (1977). Extraído de Rohmer (2000a: 124). 
explica a Maurice Baquet lo que hizo durante la tarde del domingo. La genialidad de la secuencia, para Rohmer, radica en la doble razón de que alude a una escena precisa de la película y que el relato es una mentira. He aquí la palabra "en toda su densidad", exclama Rohmer, cuando ésta se refiere a lo que vemos al mismo tiempo que lo niega. Para Rohmer, "el cine debe encontrar el medio de integrar la palabra no en el interior del mundo filmado, sino en el interior de la película" lugar solamente replanteando la relación de la palabra con la imagen.

En "Cuentos morales", Rohmer convertiría la palabra en la expresión de la resistencia entre el lenguaje y las cosas a la que se refiere Gunning, o entre la tradición y la especificidad fílmica que argumentó el cineasta en Le celluloïd et le marbre. "Cuentos morales" nace de una serie de novelas escritas por el mismo cineasta y el film debería aprovechar el estilo indirecto para convertirse al mismo tiempo en estilo directo. Con ello, Rohmer crearía un décalage entre el pensamiento y la acción en el héroe/narrador, esto es, entre la palabra y la imagen. La separación de la palabra del héroe, asincronía o desarticulación, permitió a Deleuze concebir, a partir de los mismos films de Rohmer, el derrumbe sensoriomotor propio de la modernidad en el acto del habla, donde éste "se repliega sobre sí mismo, ya no es una dependencia o una pertinencia de la imagen visual, pasa a ser una imagen sonora de pleno derecho" 12 . La desarticulación implicaría concebir el film en el cierre del héroe con su propio pensamiento; el desarrollo del film, por tanto, obedecería al mismo pensamiento del héroe. Esta fue sin duda la ambición del cineasta: "En los Cuentos Morales he querido mostrar deliberadamente la relación de uno consigo mismo. Por ese motivo están en primera persona y tienen un comentario. Tratan del proceso que alguien puede tomar respecto a sus gustos, sus deseos, sus sentimientos, respecto a sí mismo. El personaje habla de sí y se juzga; está filmado en tanto que se juzga"13. En el mismo sentido, distintos autores (Bonitzer, Ramasse, Salvadó, M. Serceau, D. Serceau ${ }^{14}$ se han aproximado a la primera serie de films de Rohmer. Por un lado, los estudios ponen en discusión la desarticulación de la palabra del héroe como elemento significante en el análisis de la puesta en escena: la relación que toma el off como subjetivo, objetivo, o ajeno al diálogo del personaje consigo mismo, la palabra como separación en sujeto y objeto, como superposición al pensamiento o constructora del mismo. Por otro lado, los estudios sitúan a Rohmer en la tradición del amor cortés y al uso del lenguaje en el teatro de Shakespeare, Beaumarchais y sobre todo, Marivaux: la relación que lo dicho, lo entredicho y lo prohibido y su relación con la verdad - con el deseo- del pensamiento del héroe. Tanto el final de Ma nuit chez Maud, cuando Trintignant se cruza con Maud en la playa, como el final de L'amour l'après-midi, cuando Frédéric abandona a Chloé para regresar con Hélène, ambos films ponen en evidencia cómo la confesión sólo puede darse por un rodeo del lenguaje, por todo lo que no podrá decirse y que debe permanecer escondido.

En síntesis, la palabra de "Cuentos morales" fue objeto de estudio para el análisis textual y formal en la medida en que se asumió el film como pensamiento del héroe/

11 Rohmer, "Pour un cinéma parlant", Les Temps Modernes (1948). Extraído de Rohmer (2000a: 51-56).

12 Deleuze (2004: 320).

13 Éric Rohmer a Biette, Bontemps y Comolli, “L'ancien et le nouveau: Entretien avec Éric Rohmer”, Cahiers du Cinéma, núm. 171 (1965). Extraído de Pasolili y Rohmer (1970: 66). 
narrador. Pero, siguiendo las palabras del mismo Rohmer, ¿qué hay del proceso que lleva al juicio de sí mismo? ¿No son los gustos, deseos y sentimientos de uno mismo una construcción hecha a partir de la mirada del otro? Y si como señala Bonitzer "no deberemos buscar la verdad en lo que [el héroe] dice y en lo que muestra, sino en lo que calla y en lo que esconde" "is ¿́mo aproximarnos a esta verdad del relato del héroe sino fuera del sujeto? Si el estudio sobre la palabra en "Cuentos morales" no puede prescindir de la negación o la mentira del héroe, tampoco puede hacerlo de todo lo que ocurre fuera del propio sujeto, donde la feminidad, que afecta a la moral del héroe y condiciona su palabra, se convierte en la figura privilegiada.

\section{La mano sobre la rodilla de Claire}

Serge Daney en Perseverancia identifica la ruptura que Deleuze define entre el cine clásico y la modernidad como un desplazamiento entre un cine fundado en el ideal (masculino) y un cine de la alteridad. Según el fundador de la revista Trafic, entre 1960 a 1980 el cine no sólo dejaría aparecer a las mujeres, sino que éstas exigirían otro modo de ser filmadas. "El cine se ocupó de eso durante quince o veinte años y fue lo que en esa época transformó el lenguaje", añade Daney ${ }^{16}$. A partir de Ingmar Bergman, de Roberto Rossellini o de Jean-Luc Godard, el cine halló en la feminidad no un objetivo al que llegar como elemento subordinado al relato, como lo hizo el cine clásico, sino el espacio de un diálogo con la mirada misma, con lo invisible y lo desconocido. Como anunciábamos en otro trabajo ${ }^{17}$, en el cine de la Nouvelle Vague, la feminidad se convierte en el espacio que permite al cineasta dialogar con la naturaleza propia del cine: la exploración del plano/contraplano en Godard a través de Ana Karina para plantear la necesidad de ver antes de explicar, la dialéctica de lo imaginario y lo real en François Truffaut, o entre el cine como proceso y tiempo real y la obra de teatro como monumento atemporal y fantasía en Jacques Rivette.

En "Comedias y proverbios" la feminidad se convirtió en la figura de búsqueda de Rohmer entre el campo y el fuera de campo, entre el azar del tiempo real y la creencia en un más allá del real. Situándose en el intervalo, en el diálogo entre elementos de la imagen, la feminidad planteaba de esta manera la pregunta ontológica del cine y pedía al cineasta la suspensión de la acción para empezar a plantear el cine en términos de visión (la tesis de Daney y de Deleuze coinciden en este punto). Pero como anunciábamos en la introducción, este proyecto fue con la mirada a la mujer deseada de "Cuentos morales" que arrancó. Sin duda, la presencia de Maud, Chloé, Claire o Haydée determinan una decisión, esto es, el héroe dará a sus acciones

"No deberemos buscar la verdad en lo que dice y en lo que muestra, sino en lo que calla y en lo que esconde" (Bonitzer, 1991: 15).

16 "La modernidad asumió la carga de algo totalmente distinto: un hombre y una mujer, la guerra de los sexos y una eventual resolución de esa guerra. En eso se invirtió toda la energía artística y creadora, entre 1960 y 1980. Había que cambiar el cine del ideal, es decir el cine masculino (solo los hombres tienen ideales), por un cine que dejara aparecer a las mujeres. [...] Para los cineastas de la Nouvelle Vague, las grandes conmociones fueron la aparición de Brigitte Bardot, la foto de Harriet Andersson o Mónica Vitti (estábamos lejos de Michèle Morgan), imágenes de mujeres que imponían otro modo de filmarlas. El cine se ocupó de eso durante quince o veinte años y fue lo que en esa época transformó el lenguaje” (Daney, 1991: 113-114). 
un sentido de acuerdo con sus pensamientos, lo que responde al encadenamiento sensoriomotor de la imagen-movimiento deleuziana. Pero antes de tomar la decisión, antes de guiarse por la palabra adecuada y asumir la acción, invade al héroe una parálisis provocada por su deseo de aproximación. Frente a ella, asistimos a una suspensión que imposibilita al héroe establecer una relación con la imagen mediante la palabra y es sólo en términos de mirada que el héroe puede expresarse.
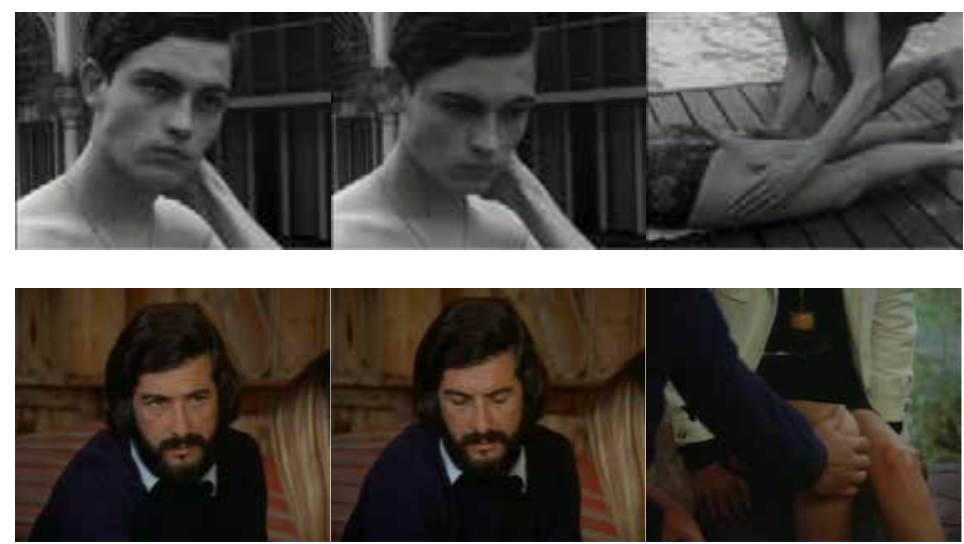

La carrière de Suzanne (1963) / Le genou de Claire (1970)

Al final de La carrière de Suzanne (1963), Bertrand reencuentra a Suzanne en la piscina. Suzanne, la joven seductora que Bertrand conoció en el café Le Luco de Saint Michel, aparece con su nuevo prometido. Vemos a Suzanne tumbada, pasiva, dejando que las manos de su nuevo amante la llenen de crema. En el contraplano de la acción, la mirada del héroe se revela próxima e insólita en un film sin primeros planos. "La mirada de Bertrand es el fin de la mirada, la extinción del sentido", escribe Ramasse ${ }^{18}$. Si la afirmación de Ramasse habla del fin de la mirada es porque hasta el momento ésta fue construcción del pensamiento del héroe. Aquí, sin embargo, la mirada escapa a su control. El deseo aparece como otra manera de ver más allá del pensamiento del héroe, y si la mirada apela a la "extinción del sentido" es porque el ojo ya no quiere ver, sino que desea tocar. Es el fenómeno que Rohmer explora a través de Jérôme en Le genou de Claire, cuando el héroe satisface el deseo fetichista de acariciar la rodilla de Claire. La dilatación temporal generada por el gesto nos sitúa frente a uno de los fragmentos más incómodos de la obra de Rohmer. La cámara se aproxima hacia la rodilla de Claire, desaparecen las palabras, sólo escuchamos la respiración de la joven y la lluvia que permitió a Jérôme refugiarse con la chica - la misma lluvia metaforiza las lágrimas de Claire- De nuevo, en el contraplano, Rohmer presta atención a la mirada del héroe, que ahora oscila entre el rostro y la rodilla, entre la imagen y la carne, entre el ver y el sentir. He aquí la suspensión de la mirada del héroe, sujeta a la indecisión, al silencio de la palabra y al tiempo de la misma suspensión. 
La caricia de Jérôme nos conduce a la afirmación de Maurice Merleau-Ponty según la cual "la mirada envuelve, palpa y ciñe las cosas visibles". Si el fenomenólogo se sirvió de lo tangible para pensar la mirada fue porque vio necesario pensar al ser que mira como presencia en el mundo y por tanto como vidente y visible al mismo tiempo. Jean-Paul Sartre ya se refirió a ello en L'Être et le néant: "El 'ser-visto-por-el-otro' es la verdad del "ver-al-otro"". ${ }^{19}$ Y Merleau-Ponty añade en Le visible et l'invisible: "Puesto que ver es palpar con la mirada, es preciso que la visión se inscriba también en el tipo de ser que nos revela, es preciso que el que mira no sea ajeno al mundo que mira". ${ }^{20}$ Grosso modo, Merleau-Ponty explica que el yo y el mundo no existe sólo para ver, sino para ser visto y en la medida que soy visto entre las cosas, puedo ver. Las imágenes del deseo del héroe, por lo tanto, no se desarrollan únicamente como aproximaciones al otro, sino como un retorno en la mirada, pues es la presencia del otro lo que hace levantar los ojos al héroe. "Lo que vemos no vale — no vive - a nuestros ojos más que por lo que nos mira", escribe Didi-Huberman para referirse a ello ${ }^{21}$. Esto explicaría la "extinción del sentido" en el primer plano al final de La carrière de Suzanne o en la oscilación de la mirada de Jérôme frente a Claire, pero sobre todo, en cómo Rohmer filma el cuerpo deseado. Como un objeto lejano, intocable, obra de arte. Claire - el nombre no pasa desapercibido - aparece primero en una fotografía y después, como un lienzo cuando el héroe se fija en su rodilla expuesta a la luz. El caso de La collectionneuse es parecido: la primera mañana que Adrien ve a Haydée, ésta aparece en su lejanía, pero el héroe no tardará en acercarse a ella cada vez más, culminando esta aproximación en la orilla de la playa, en una secuencia en la que Rohmer no esconde la referencia de Sommaren med Monika (Ingmar Bergman, 1953).

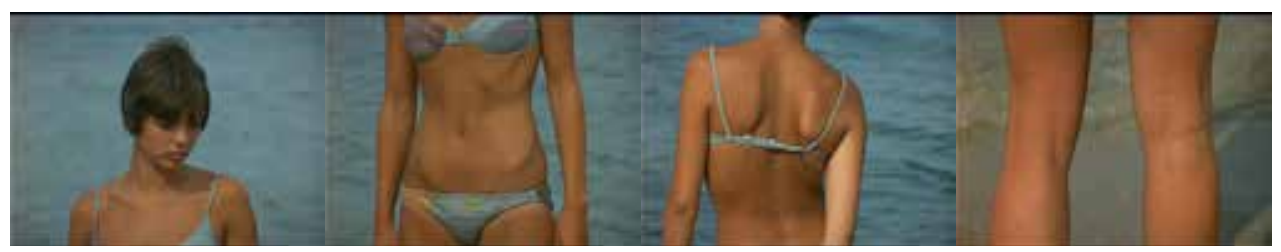

La collectionneuse (1967)

En La collectionneuse Rohmer traduce lo tangible en una aproximación formal. De este modo se presenta Haydée en el prólogo, por un corte seco y rápido, Rohmer rompe el cuerpo de Haydée en cuatro planos: un cambio de dirección en el caminar de la joven, una panorámica que sigue los contornos de su cuerpo deteniéndose al ombligo, y después, el dorso, estático, y el reverso de las rodillas hasta llegar al cuello. Las imágenes ofrecen trozos, zonas, fragmentos de un cuerpo sin unidad sintética. Vemos a Haydée por esta desunión, por la enumeración anatómica con la que, según Jean-Luc Nancy, el cuerpo se hace interminable y cambiante ${ }^{22}$. Rohmer

Sartre (2008: 360).

20 Merleau-Ponty (1970: 166, 168).

21 Didi-Huberman (1997: 13).

22 Véase Nancy (2007). 
muestra a Haydée como una sucesión de planos, como un découpage por tanto sujeto a la mirada del voyeur por medio de un encuadre limitado, rítmico y luminoso. Asistimos a la mirada subjetiva de Adrien sobre un cuerpo que el protagonista tilda de coleccionista de hombres, al mismo tiempo que sobre Haydée recae una mirada que se aleja de la percepción subjetiva y se contagia de las propiedades de la imagen, de un cuerpo "formalmente tratado", sin palabras y sin la continuidad temporal con la que se desarrollan los otros dos prólogos que también introducen la cinta. En síntesis, la proximidad y el corte al cuerpo de la heroína apelan a lo tangible, a lo perceptivo, al deseo que el héroe no puede seguir mirando, mientras que, paradoxalmente, la ausencia de palabras exige la visión como única forma de seguir en el relato.
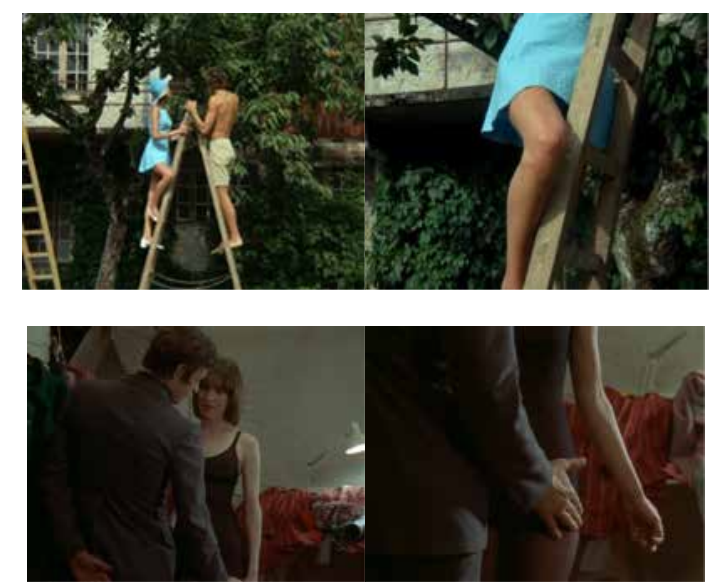

Le genou de Claire (1970) / L'amour l'après-midi (1972)

Como en la primera aproximación de Jérôme a Claire, la presencia de Chloé también cambiaría la visión de Frédéric en L'amour l'après-midi y Rohmer lo explicita cuando cambia la posición de cámara y la lente en el momento en que la observación se transforma en deseo de tocar. Este cambio tiene lugar cuando el héroe fija la mirada en la línea del cuerpo de Chloé, la curva que el héroe contempla como una escultura, la misma imagen que Man Ray daba a Kiki de Montparnasse la forma del violonchelo. Pero como en el gesto fetichizado de Jérôme o la sucesión de fragmentos del cuerpo de Haydée, la misma imagen del deseo de Chloé inclina al héroe a ver lo terrible. He aquí la imagen del abandono, el plano cenital de las escaleras del apartamento de Chloé: la bajada al subconsciente o la entrada al interior de la conciencia. La imagen escapa al planteamiento formal del resto del film, se trata del único plano que, en palabras de Néstor Almendros, el director de fotografía del film, escapa a las normas del ángulo y el movimiento de cámara propios de la visión humana ${ }^{23}$.

La escalera de caracol de L'amour l'après-midi expresa el abismo, el vértigo de la mirada que sufren todos los héroes de "Cuentos morales". Sobre la imagen resuena 
el leitmotiv con el que Hitchcock planteó en Vertigo (1958) la atracción de Scottie (James Stewart) por Madeleine (Kim Novak). Deleuze consideró a Hitchcock como el cineasta que pone en crisis el sistema de la imagen-acción. Como encontramos escrito al final de L'image-mouvement, el personaje hitchcockiano padece de incapacidad motriz (la amnesia en Spellbound [1945], la pierna rota en Rear Window [1954] o la misma acrofobia en Vertigo), su situación imposibilita su participación en la acción y entonces el personaje se abandona a una visión: el héroe o heroína se convierte en personaje al mismo tiempo que en espectador. He aquí la ventana a través de la cual mira el fotógrafo en el patio de Rear Window o la posición de los personajes en toda la trama de The Trouble with Harry (1955). Vertigo plantea en la tensión erótica de Scottie y Madeleine una relación de espectador-objeto de arte, pero lo que sustenta la tensión es precisamente la mirada de Madeleine. Ésta aparece en su presentación en el restaurante. Vemos a Madeleine desde lejos; la cámara, suspendida en el aire, se aproxima poco a poco a ella, que se levanta mientras permanece encuadrada en el marco de la puerta que la separa de la barra del restaurante desde donde Scottie, como espectador, la observa. Antes de que Madeleine salga del restaurante, Hitchcock excita un casi encuentro de miradas, positivando la imagen, enfatizando el rojo del tapiz del muro del restaurante que rodea la heroína. Ahora ella, objeto de mirada de Scottie, nos mira: la lejanía del rostro de Madeleine se presenta próximo, como "manifestación lejana". A partir de este momento, un movimiento de hipnosis arranca, metaforizado por el trayecto en coche con el que Scottie seguirá a Madeleine. Romper la distancia espacial llevaría a Scottie a establecer una experiencia de temporalidad. Es de esta manera que, a partir del concepto de "aura" de Walter Benjamin, lo describe George Didi-Huberman: "en el momento que percibimos cómo la imagen nos mira, la experiencia de tiempo sobrepasa la impresión de una distancia nunca superada".

Si el héroe de "Cuentos morales" no llega a establecer una experiencia de tiempo con la feminidad es porque antes de dejar ser mirado por el otro, antes de llevar el deseo incontrolable a una experiencia de visibilidad, prefiere mirarse a sí mismo. En la mirada al espejo, el héroe se ve observado por su propia conciencia en $L a$ collectionneuse y en L'amour l'après-midi. Y si en Le genou de Claire Jérôme se abre a esta experiencia de tiempo, ésta desaparece cuando terminan las lágrimas de Claire, cuando ya no existe un consuelo que atender; porque lo que para Jérôme fue un gesto de deseo, para Claire fue de consolación. Así lo expone el héroe después de esta secuencia a su amiga Aurora. Ella lo escucha, espectadora de su historia. Aurora, novelista, fue quien empujó a Jérôme a realizar su aventura. "Si no hubieras estado allí, no hubiera pasado nada aunque hubiera conocido a las chicas de un modo u otro", dice Jérôme a Aurora. El héroe justifica de este modo su acción y su moral: asumiendo que se dejó llevar por una ficción que no tiene nada que ver con su propia vida. En La collectionneuse, Adrien decide tomar sus vacaciones para no hacer nada, sólo leer — no casualmente, las obras de Rousseau - "Si no leyera, pensaría. [...] Un libro me hace pensar en cierta dirección, la del libro. Lo que no quiero es pensar en mi dirección", le dice a su amigo Daniel. Sin embargo, la nueva dirección no lo llevaría a la nada, sino hacia la apertura a toda disponibilidad, culminando de esta manera con el deseo de Haydée. Es la apertura de la que emerge el deseo que esconde Frédéric en L'amour l'après-midi: leyendo un libro de ficción en el metro, porque "el periódico no moviliza lo suficiente mi atención y sobre todo porque no me ayuda a escapar del presente". Si Frédéric es capaz de sostener la 
mirada sobre las chicas generando un "misterio que antes ignoraba", es porque cree pertenecer a otro mundo, un mundo al que la muchedumbre, tomando la palabra de Baudelaire, también lo ayuda, permitiéndole, como el mar, "navegar sin sumergirme en ella", "en su superficie en solitario". Se trata del mismo "estado de pasividad, de disponibilidad total" que busca Adrien en sus vacaciones, decidido a mirar hacia el mar únicamente: "Me abandonaba a la única fascinación de observar el movimiento de la sombra y de la luz, entrando en un letargo que el baño prolongaba". La ficción que abre la presencia en la muchedumbre o la idea de un espacio vacío conduce a la visión suspendida entre el real y el imaginario, entre el pensamiento y el deseo, una visión que ocupa un intervalo entre dos mundos que nunca podrían encontrarse y que el cuento moral plantea mediante una clara oposición: el mundo de la chica rubia, cándida y católica, el de la morena seductora y divorciada. Y sin embargo, ¿en qué medida esta dicotomía es tan evidente? La feminidad no sólo platearía otro modo de ver, sino que, en la medida en que ocupa el intervalo que acabamos de definir, cuestiona la decisión moral del héroe, empujándolo a la duda de su pensamiento.

\section{4. "Una era el error, la otra la verdad". Ambigüedad femenina en "Cuentos morales"}

El joven narrador de La boulangère de Monceau (1963) se cruza a menudo con una desconocida por la calle Villiers de París. Tras varios encuentros, llega un primer intercambio de palabras entre los dos. La joven se llama Sylvie, pero esa misma tarde no tiene tiempo para una cita. Pasan los días y de nada sirve esperar ni dar vueltas en su búsqueda, Sylvie no aparece. Durante ese tiempo de ausencia, el héroe conoce a Jacqueline, la panadera, a quien podría seducir como nunca se atrevería a abordar a Sylvie. El mismo día que el héroe concertó su primera cita con Jacqueline, saliendo de la panadería el joven se encuentra con Sylvie. "Mi elección fue moral. $\mathrm{Al}$ reencontrar a Sylvie, perseguir a la panadera sería un vicio, una aberración. Una era la verdad, la otra el error. En este momento al menos lo creí así". Desde el off del héroe quedaría claro que, a pesar de la convicción por su decisión, existiría una duda, una duda que la imagen también muestra: Sylvie, la muchacha que sedujo al héroe por su andar hierático y decidido, aparece caminando con una muleta — Sylvie desapareció porque tuvo un accidente- En el reencuentro no vemos el cortejo, ni el primer beso, tan sólo el principio de una cena y la voz del héroe anunciando que ambos se casaron seis meses después. ¿De veras fue Sylvie la verdad y Jacqueline el error? ¿Acaso no habita también el error en la decisión moral?

Ma nuit chez Maud es el otro film de la primera serie en el que Rohmer sitúa al espectador frente al conocimiento de ambas feminidades, planteando la misma incertidumbre que en La boulangère de Monceau. En concreto, el film explica el devenir de la elección del héroe. La elección parece clara: Françoise encarna el compromiso y los mismos modales del héroe, es el rostro que, como en el resto de "Cuentos morales", indica el camino a seguir, la apuesta segura. Aceptar a Françoise y no a Maud supone para el héroe/narrador (Jean-Louis Trintignant) abandonar la tentación de un amor contrario a sus convicciones y creencias. Pero si Rohmer presenta a Françoise en la iglesia de Clermont-Ferrand no es sólo para mostrarnos que es el único espacio donde un católico podrá encontrar el amor, sino porque en Françoise reverbera la misma contradicción moral que invade al héroe. Françoise 
y el héroe cruzan por primera vez su mirada durante la misa. En el plano, Rohmer mantiene el encuadre simétrico y frontal al altar donde el cura recita el Padrenuestro; en el contraplano, Trintignant busca la mirada de Françoise. Los dos espacios anuncian la premisa con la que se mueve el tercer cuento moral y cuya afirmación hace el narrador durante la cena en el apartamento de Maud: la religión aporta al amor, pero el amor también a la religión. Pero lo más relevante viene dado por la ambigüedad de la puesta en escena, donde las palabras del sacerdote, leídas en el tránsito entre dos perfiles, anticipan, por un lado, la tentación a la que terminará cayendo el protagonista; por otro lado, remiten al conflicto moral que también habita en Françoise y que sólo llegamos a conocer al final del film con una mirada de Françoise al narrador tras el reencuentro de Maud.

En Sunrise: A Song of Two Humans (1927), Murnau convertía el lago en el espacio ideal y temido a la vez, como el campo, el infierno y el paraíso de los amantes de City Girl (1930), la prisión y el idilio en Tabou (1931). Si Rohmer define a Murnau como el cineasta que mejor entendió la especificidad del espacio fílmico ${ }^{24}$ fue porque vio que su cine no consistía en encerrarse en un mundo, sino que partía de un mundo para volver hacia el punto de partida con una nueva mirada. Sunrise hace pedagogía de este fenómeno: no sólo el lago aparece dos veces, sino que, después del reencuentro de la pareja, las mismas escenas se repiten una y otra vez con variantes y sentidos opuestos. De esta manera, la nueva escena sustituye el recuerdo que el espectador guarda de la escena precedente, al mismo tiempo que abre la escena hacia una nueva posibilidad. En L'amour l'après-midi, Hélène, de rostro blanquinoso, frágil, prudente y tranquila, parece encarnar el arquetipo de una feminidad benévola, siendo a la vez el único personaje madre de familia, hecho que asegura una estabilidad en el sí de la pareja. Pero, ¿qué hace Hélène a lo largo de sus mediodías, los mismos en los que Frédéric se encuentra con Chloé? Como en La collectionneuse, donde Carole expresa el deseo de permanecer alejada de Adrien durante las vacaciones; como la vida anterior de Françoise que el narrador (y el espectador) cree descubrir con una sola mirada; los días de Hélène quedan fuera de campo y la frialdad de los besos cuando Frédéric regresa a casa abren la duda de su fidelidad.
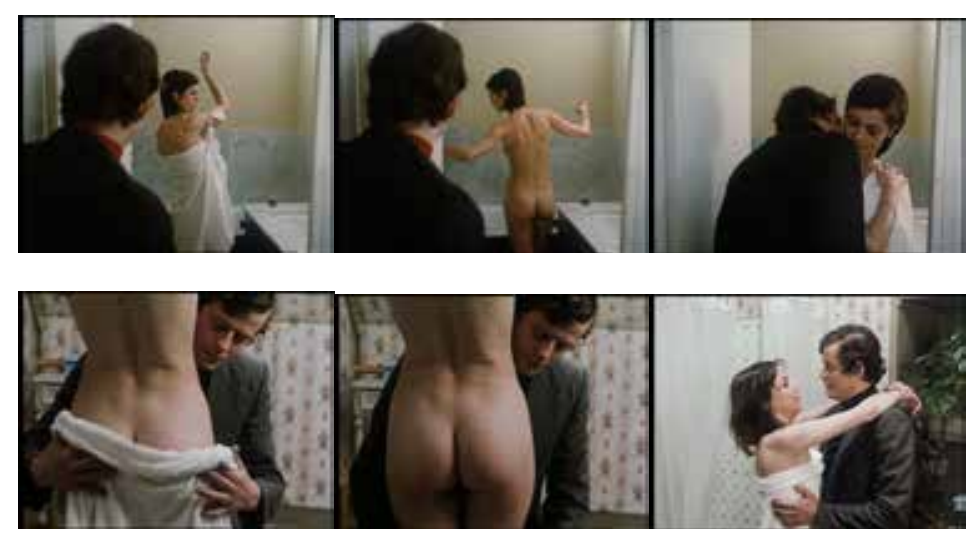

L'amour l'après-midi (1972) 
Como en Murnau, es por la repetición y su relación con el recuerdo que Rohmer pone en duda la evidencia: el desnudo de Chloé del final del film remite a las imágenes que vimos al principio, cuando François ve a Hélène salir de la ducha y se aproxima a ella para besarla. De este modo, las imágenes que alertan del peligro de culminar el deseo, corresponden a las mismas del amor conyugal. Porque, ¿qué hay de la admiración a la maternidad desconocida de Chloé, de la prudencia de Jacqueline o del recuerdo del amor perdido de Maud? ¿Acaso no remiten al mismo universo moral del héroe? ¿Acaso las posturas y actitudes de la femme fatale en "Cuentos morales" no contienen también las propias de la vida conyugal?

\section{A modo de conclusión}

Tal y como se expone en L'amour l'après-midi, el problema del héroe del cuento moral reside en la imposibilidad de establecer un diálogo con el inconsciente. De este modo lo lee también Jean-Claude Brisseau, el gran autor del psicoanálisis que en 1989 ofrecía al público francés un "último cuento moral": Noce Blanche. Exprostituta, de 17 años, criada lejos de sus padres, Mathilde es la tentación de François, su profesor de filosofía. Intrigado por la joven, François rompe con el razonamiento del héroe rohmeriano y acepta la separación de su matrimonio. Después se arrepentirá, y sin embargo, descubrimos al final del filme que Mathilde no engañó a François cuando le dijo que moriría por él. Brisseau homenajea a Rohmer cuando, después de la primera crisis con Mathilde, asistimos al visionado de Le rayon vert en una de sus clases del instituto. En el momento en que el rayo verde aparece en el film, François dirige su mirada hacia la silla vacía que durante el curso ocupaba Mathilde. Pero no es sólo él quien sufre, pues como Delphine, Mathilde también espera, perseverante, la llegada del amor, y muere por no conseguirlo. Brisseau crea de este modo un vínculo entre la primera y la segunda serie de Rohmer, destapando lo que Rohmer deja en la duda. ¿Por qué Rohmer se inclina por permanecer en esta duda y no por resolverla?

Tras la presentación de Pierrot le fou (1965), Godard declaraba que lo propio del narrador francés - refiriéndose a Flaubert y a Proust - era que, a diferencia del americano, no sabe narrar historias. Como la literatura francesa, los grandes filmes de la modernidad tenían que seguir otro modelo, y éste fue el de permanecer en el malentendido. $\mathrm{O}$ en su desconocimiento, así como lo consideró Godard tras el estreno de Vivre sa vie (1962): "Prefiero buscar en lo que no conozco que hacer algo que ya conozco" 25 . Al principio de estas páginas nos preguntábamos cómo el cineasta define un proyecto estético en este sentido y tomamos el deseo y no el pensamiento del héroe - donde la mentira funciona como el malentendido - como el terreno para abordarlo. Pero si, tal y como han demostrado los autores citados anteriormente, el pensamiento se inclina por una lectura ambigua desde el punto de vista del héroe/ narrador, en este artículo defendimos que es en la apertura al otro y en la presencia de la feminidad en particular que aparece la ambigüedad del pensamiento.

A partir de Murnau, Rohmer defiende la existencia de una expresión ambigua que sólo pertenece a la imagen cinematográfica. "El cine nos arroja a los ojos un todo del que es posible extraer múltiples significaciones posibles", y añade más 
abajo: "El tema del deseo es cinematográficamente uno de los más ricos, porque exige que se establezca ante nuestros ojos toda la distancia que, en el tiempo o en el espacio, separa la vigía de su presa" ${ }^{26}$. En el tercer y cuarto apartado vimos cómo esta distancia en el tiempo y en el espacio explica, por un lado, una apertura a la observación y, por otro lado, una ambigüedad por el rodeo de la misma observación. Pues como vimos, Rohmer presenta a Haydée como un cuerpo al que aproximarse, pero también como imagen de contemplación, expuesto a la luz, en el silencio y la distancia; la imagen de Claire en la escalera aparecía también como la observación de un lienzo, al mismo tiempo que como el objeto de un fetiche. Y si Rohmer plantea la feminidad de "Cuentos morales" como una relación de artista y de obra, al mismo tiempo, la misma relación de distancia y proximidad sitúa a la feminidad en lo que empuja al héroe a la duda de su pensamiento.

En resumen y retomando las hipótesis de partida, la visibilidad que la feminidad provoca sitúa la serie de "Cuentos morales" en la encrucijada entre la crisis y el devenir del relato, entre el clasicismo y la modernidad mediante la cual se ha definido siempre la obra de Rohmer. Para ello, fue significativo que el cineasta convirtiera una serie novelada en una serie de films, lo que permitió a Rohmer abordar la acción del héroe desde la desarticulación de su propia palabra. Sin embargo, esta desarticulación aparece en la medida en que el film privilegia una inquietud por ver generada por la presencia del sujeto femenino. Frente a la resistencia de la palabra del héroe (mirada fundada en el pensamiento), el deseo que obra mediante la alteridad anuncia una nueva mirada (mirada del deseo) que, según Alexandre Astruc, empezaba a darse con la Nouvelle Vague: el abandono del tema del filme en detrimento de "una mirada sobre los filmes, una mirada preocupada por lo esencial" ${ }^{27}$. En el plano/contraplano de Françoise y Trintignant en la iglesia de Clermont-Ferrand, en la mano que recorre la rodilla de Claire, en la disponibilidad de Haydée en el agua o en la curva del cuerpo de Chloé. En todos esos encuentros el acontecimiento al que se enfrenta la mirada supera la palabra del héroe, su acción a desarrollar y el relato requiere el abandono para dejar que trabaje sólo la mirada desde la misma inquietud que genera todo aquello que el héroe no puede ver con claridad. He aquí la "extinción del sentido" que Ramasse vio en la mirada del héroe al final de La carrière de Suzanne, he aquí la ambigüedad de la distancia entre el ver y el tocar que exige la mirada del deseo, donde la feminidad aparece como la figura de la densidad que Rohmer reclamaba a la palabra en el cine: una negación de lo que se evidencia para replantear lo visible. En este sentido, en suma, mediante feminidad en "Cuentos morales" no sólo la palabra y la imagen se convierten en formas que resisten la una a la otra, sino que, siguiendo la observación de Gunning, nos situamos frente a la resistencia entre la mostración y el lenguaje que definiría la especificidad del cine de Rohmer.

\section{Bibliografía}

Almendros, N. (1980). Un homme à la caméra, París: Hatier.

Bazin, A. (2008). ¿Qué es el cine? Madrid: Rialp.

Béghin, C; Romand, B. (2010). "Rohmer For Ever”, Cahiers du Cinéma, núm. 653, 24-25. 
Biette, J-C.; Bontemps, J.; Comolli, J-L. (1965). “L'ancien et le nouveau. Entretien avec Eric Rohmer", Cahiers du Cinéma, núm. 172, 32-43.

Bonitzer, P. (1991). Eric Rohmer. París: Étoile/Cahiers du cinéma.

Daney, S. (1991). Perseverancia. Reflexiones sobre el cine. Conversaciones con Serge Toubiana, Buenos Aires: El Amante.

Deleuze, G. (2003-2004). La imagen-movimiento, La imagen-tiempo, 2 vols. Barcelona: Paidós, Barcelona.

Didi-Huberman, G. (1997). Lo que vemos, lo que nos mira. Buenos Aires: Manantial.

Godard, J-L. (1998). Godard par Godard, vol. 1: 1950-1984. París: Cahiers du Cinéma.

Gunning, T. (2007). "Éric Rohmer et l'héritage du réalisme cinématographique", en Noël Herpe (ed.), Rohmer et les Autres. Rennes: PUR.

Merleau-Ponty, M. (1970). Lo visible y lo invisible. Barcelona: Seix Barral.

Nancy, J-L. (2007). 58 indicios sobre el cuerpo. Extensión del alma Buenos Aires: La Cebra.

Pasolini, P. P.; Eric Rohmer. (1970). Cine de poesía contra cine de prosa. Barcelona: Anagrama.

Ramasse, F. (1985). “L’espace des sens”, Études cinématographiques, núms. 6-7, vol. "Eric Rohmer 1", 51-62.

Rancière, J. (2005). “¿De una imagen a otra? Deleuze y las edades del cine”, en La fábula cinematográfica. Barcelona: Paidós, 129-146.

Rohmer, É. (2000a). El gusto por la belleza. Barcelona: Paidós.

-. (2000b). L'organisation de l'espace dans le Faust de Murnau. París: Cahiers du Cinéma.

- (2010). Le cellulö̈d et le marbre, Suivi d'un entretien inédit. París: Éditions Léo Scheer.

Salvadó, G. (2005). "La Mirada i la paraula en els Sis contes morals d'Eric Rohmer: estudi de la formació de la subjectivitat narratirva cinematogràfica". Proyecto de fin de carrera. Barcelona: UPF.

Sartre, J-P. (2008). El ser y la nada. Buenos Aires: Losada.

Serceau, M. (2000). Les jeux de l'amour et du hasard. París: Cerf.

-. (1985). "Éric Rohmer et la perversion du langage", Études cinématographiques, núms. 6-7 (1985), vol. "Eric Rohmer 1", 105-127.

Tassone, A. (ed.) (2003). Que reste-t-il de la Nouvelle Vague? París: Stock.

Vayone, F. (2007). "Rohmer, Renoir et le corps féminin", en Noël Herpe (ed.), Rohmer et les Autres. París: PUR, Rennes, 29-37.

Vilaró, A. (2016). "Entre la representación y la figuración. El cine de la Nouvelle Vague: una revisión histórica”, Historia y Comunicación Social, vol. 21, núm. 1, 221-239. 